\title{
Engaging consumers living in remote areas of Western Australia in the self-management of back pain: a prospective cohort study
}

Helen Slater ${ }^{1,2,4^{*}}$, Andrew M Briggs ${ }^{2,3}$, Samantha Bunzli ${ }^{1,2}$, Stephanie J Davies ${ }^{1,4}$, Anne J Smith ${ }^{1,2}$ and John L Quintner ${ }^{4}$

\begin{abstract}
Background: In Western Australia (WA), health policy recommends encouraging the use of active self-management strategies as part of the co-care of consumers with persistent low back pain (LBP). As many areas in WA are geographically isolated and health services are limited, implementing this policy into practice is critical if health outcomes for consumers living in geographically-isolated areas are to be improved.

Methods: In this prospective cohort study, 51 consumers (mean (SD) age $62.3( \pm 15.1)$ years) participated in an evidence-based interdisciplinary pain education program (modified Self Training Educative Pain Sessions: mSTEPS) delivered at three geographically isolated WA sites. Self report measures included LBP beliefs and attitudes (Back Pain Beliefs Questionnaire (BBQ); Fear Avoidance Beliefs Questionnaire (FABQ)), use of active and passive selfmanagement strategies, and health literacy, and global perceived impression of usefulness (GPIU) recorded immediately pre-intervention ( $n=51$ ), same day post-intervention (BBQ; GPIU, $n=49$ ) and 3 months postintervention $(n=25)$.

Results: At baseline, consumers demonstrated adequate health literacy and elements of positive health behaviours, reflected by the use of more active than passive strategies in self-managing their persistent LBP. Immediately postintervention, there was strong evidence for improvement in consumers' general beliefs about LBP as demonstrated by an increase in BBQ scores (baseline [mean (SD): 25.8 (7.6)] to same day post-intervention [28.8 (7.2); $P<0.005]$, however this improvement was not sustained at 3 months post-intervention. The majority of consumers (86.4\%) reported the intervention as very useful [rated on NRS as 7-10].

Conclusions: To sustain improved consumer beliefs regarding LBP and encourage the adoption of more positive health behaviours, additional reinforcement strategies for consumers living in remote areas where service access and skilled workforce are limited are recommended. This study highlights the need for aligning health services and skilled workforce to improve the delivery of co-care for consumers living in geographically isolated areas.
\end{abstract}

\section{Background}

Persistent low back pain (LBP) is poorly managed and consequently the associated health and economic burden for consumers and for society are substantial [1,2]. For consumers with persistent pain (of which in Australia, LBP represents a significant proportion of the musculoskeletal contribution [1]), less than 10 per cent of patients gain access to effective management, yet according to recent

\footnotetext{
* Correspondence: h.slater@curtin.edu.au

${ }^{1}$ School of Physiotherapy, Curtin University, Perth, Australia

${ }^{2}$ Curtin Health Innovation Research Institute, Curtin University, Perth, Australia Full list of author information is available at the end of the article
}

international data, up to 80 per cent could feasibly receive effective care [2,3]. Furthermore, reliable data indicate that the burden of persistent pain for consumers and society can be markedly reduced when available evidence-based management is implemented $[2,4]$.

Many factors contribute to this gap in healthcare for consumers with LBP, including the failure of evidence to be translated into best practice [5-7], an inadequately trained and skilled health workforce $[8,9]$ and a lack of co-ordinated interdisciplinary care [10], the latter being a favoured model for consumers with persistent LBP [11]. To obtain effective care is difficult because persistent

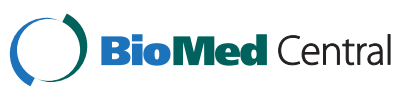


pain is often poorly understood by the general community, by educators, researchers and health professionals $[3,12]$, often resulting in stigmatization and conditions not being legitimized $[13,14]$. While there is overwhelming neurobiological evidence of changes in the brain which typically underlie persistent pain [15-18], many health professionals still view consumers with persistent pain within a framework that is biomedical rather than biopsychosocial [19], thereby missing the importance of taking a whole person approach to pain management.

Additional disadvantage exists for consumers with persistent LBP who reside in geographically isolated regions, where there is even less access to evidence-based pain services and community support $[12,20]$. This is the case for many Australians, where a large landmass is populated with low densities of people, dispersed outside of urban centres, particularly in Western Australia (WA). In this study, we targeted three remote WA locations, which included Kununurra, Albany and Kalgoorlie. Taking the shortest travel route, these towns are situated $3206 \mathrm{kms}$, $595 \mathrm{kms}$, and $409 \mathrm{kms}$ respectively away from the state capital Perth. Kalgoorlie and Kununurra lie in the most sparsely populated areas in the state, having a population density of less than 0.1 persons per sq km [21]. Developing innovative models of service delivery based on a contemporary perspective of persistent pain and aligning these models with a skilled workforce, is one strategy targeting the needs of people in these remote areas [22]. Integral to such a model of care for the management of persistent LBP is the facilitation of consumer use of active self-management strategies [23-25], as these are associated with significantly lower rates of health care utilization compared to solely using passive options $[23,26]$.

The focus in this study was the implementation of an interdisciplinary model of care for consumers with LBP living in remote areas of WA using a previously established and consumer-oriented Self Training Educative Pain Sessions (STEPS) program [25]. In a tertiary setting, STEPS has demonstrated significantly reduced wait-times, costs per new patient episode and volume of outpatient appointments and in parallel, an increased utilization of active pain management strategies and increased patient satisfaction [25]. The aim of this project was to deliver and evaluate the effectiveness of a modified STEPS program (mSTEPS) to consumers with persistent LBP living in geographically isolated areas of WA.

\section{Methods}

\section{Study design/setting/population}

Consumers from three remote WA centres (Kununurra, Albany and Kalgoorlie) were invited to attend mSTEPS in their area through flyer advertisements distributed by Rural Health West (rural health medical services) and
Arthritis and Osteoporosis WA, the peak advocacy organization for musculoskeletal disease in WA. The three mSTEPS interventions were run during 2010-2011. Those who consented to participate in the evaluation component of the intervention were enrolled in a prospective cohort study. Inclusion criteria required consumers to be able to give voluntary, informed consent for the collection of data and to have persistent LBP. Participants who were not fluent in written and spoken English were excluded from the study. The study was approved by the local Institutional Ethics Review Committees and adhered to the Code of Ethics of the Declaration of Helsinki.

\section{Participation, consent and anonymity}

Eighty consumers and carers registered and attended mSTEPS. Excluding carers from whom data were not collected, 55 consumers were recruited. Of this number, 4 were excluded, 3 of whom were blind and could not complete the data requirements and one of whom did not meet the inclusion criteria (no LBP). The remaining 51 consumers consented to use of their data for the purposes of this study.

At baseline and immediately prior to mSTEPS (i.e.; same day), consenting participants completed a uniquely-coded battery of questionnaires. The educational team remained blinded to the data collection, entry and analysis. At 2.5 months post-intervention, consumers were mailed a post-course questionnaire set with the same unique ID codes, with instructions to complete and to return within 2 weeks (i.e. by 3 months post). Non-responders were contacted by phone on not more than 2 occasions, to request the completion of the post-course questionnaires. In a related study, a subset of 14 of these 51 consumers drawn from each of the 3 locations were also purposively sampled and interviewed in order to better understand their experience of access to health information and services and use of self-management strategies [27]. To contribute to sustainability, the Albany mSTEPs intervention was captured on DVD and provided to MSTEPS consumers post 3 month data collection.

\section{Study intervention}

The mSTEPs program involved the same components as the original STEPS model [25], with the modules delivered in a more compressed format of 6.5 hours over a single day (these components are summarized and presented as Additional file 1).

\section{Outcome measures}

A battery of self-report questionnaires was administered to participants at baseline, and this battery was repeated at 3 months after mSTEPS (Table 1). In addition, on the same day and immediately following mSTEPS, one measure 
Table 1 Self report measures administered to consumers with low back pain

\begin{tabular}{|c|c|c|c|}
\hline \multicolumn{4}{|c|}{ Intervention time points } \\
\hline Self report measures & Baseline (pre-intervention) & Same day post post -intervention & 3 months post- intervention \\
\hline Demographics & $\nabla$ & & \\
\hline Pain duration/intensity & $\square$ & & $\nabla$ \\
\hline Functional limitations & $\nabla$ & & $\nabla$ \\
\hline Health care utilisation & $\nabla$ & & $\nabla$ \\
\hline Use of self management strategies & $\nabla$ & & $\square$ \\
\hline DASS $^{+}$ & $\nabla$ & & $\nabla$ \\
\hline $\mathrm{CSQ}^{\S}$ & $\square$ & & $\nabla$ \\
\hline BBQ & $\nabla$ & $\square$ & $\nabla$ \\
\hline $\mathrm{FABQ}^{*}$ & $\nabla$ & & $\square$ \\
\hline HeLMS & $\nabla$ & & \\
\hline GPIU & & $\nabla$ & \\
\hline
\end{tabular}

A battery of self-report measures was administered to consumers with persistent low back pain who lived in three remote regions of Western Australia. Measures were recorded at baseline (pre-intervention) and measures of specific parameters were repeated at post-intervention (same day and/or at 3 months) DASS: Depression, Anxiety, Stress Scale ( ${ }^{\dagger} 2$ top loading items from each scale); CSQ: Coping Skills Questionnaire ( ${ }^{\S}$ subscale 2: catastrophising); BBQ: back pain beliefs questionnaire; FABQ: fear avoidance beliefs questionnaire ( ${ }^{*}$ work and physical activity subscales); HeLMS (Health Literacy Measurement Scale); GPIU: Global Perceived Impression of Usefulness.

related to back pain beliefs was repeated (Table 1) and participants were also asked to rate the usefulness of the intervention, as described below. To limit responder burden, and given the considerable time required for completion of the baseline battery of questionnaires (30-40 minutes at baseline), the same day post measures were limited to these 2 items. Additionally, it was anticipated that repeating the full battery at this time point would not provide any meaningful data at that time. The battery was designed to align with the core domains and measures of outcomes as outlined in the IMMPACT recommendations [28] and which, while directed at clinical trials, also have broad utility for all clinical pain research $[29,30]$.

\section{Demographic data}

Consumers' age, gender, marital status, country of birth, language spoken, level of education, employment status, medical benefits eligibility, injury compensation status and injury litigation status were recorded.

\section{Healthcare utilisation}

Consumers were asked whether they had ever sought care for their back pain in the past and if so, to indicate from whom, by selecting from pre-specified categories of healthcare practitioners including doctors, allied health professionals and alternative practitioners, using an 'other' category $[23,25]$.

\section{Clinical data}

Elements of the Nordic Musculoskeletal Pain Questionnaire [31] were used to confirm LBP prevalence and to measure pain duration. Mean LBP intensities (current; past week; past month) were measured using an 11 point numerical rating scale (NRS) of 0 to 10 , with the left anchor $0=$ no pain and the right anchor at $10=$ maximal imaginable pain [32]. Consumers were asked to selfnominate up to 3 functional activities that they were unable to do or had difficulty with due to their LBP and to rate the level of difficulty using an 11 point numerical rating scale (NRS) of 0 to 10 , with the left anchor $0=$ unable to perform activity; and the right anchor at $10=$ able to perform activity at pre-injury level. As participants were not asked to re-estimate the level of difficulty with the same activity at post mSTEPS, and thus a change in activity-specific disability could not be calculated, we chose to tabulate the frequencies of reported difficulties with commonly listed activities, and to use the data for a baseline sample description only.

\section{Use of self-management strategies}

Consumers indicated their use of active and passive pain coping strategies when responding to the question 'Which of the following approaches helps to relieve your back pain?' (Table 2). These coping strategies were based on those originally described by Brown and Nicassio [33] and subsequently represented [23,25] as four categories: active behavioural, active cognitive, passive behavioural and passive conventional. Consumers could select as many strategies as they considered relevant to their persistent LBP. Definitions for these categories have been well documented elsewhere [23,25].

\section{Pain-related cognitive-behavioural instruments} Coping skills questionnaire (subscale 2; catastrophizing) The catastrophizing subscale of the Coping Skills Questionnaire (CSQ)[34] was used to assess general pain 
Table 2 Use of self management strategies for consumers with low back pain

\begin{tabular}{llll}
\hline & \multicolumn{1}{c}{ Self management strategies } & \\
\hline Active behavioural & Active cognitive & Passive & Passive conventional \\
Exercised & Relaxation & Avoided activity & Took medications \\
Daily walking & Distraction & Rested & Used brace \\
Corrected posture/stretches & Prayer & Hot bath/shower & Used TENS machine \\
Worked & Meditation & Hot/cold packs & Physiotherapy treatment (manipulation) \\
Did usual tasks & Reduced stress & Massage & Chiropractry \\
Modified activities & Ignored pain & Smoked & Acupuncture \\
Did small bits often & Improved diet & Drink Alcohol & Procedures (e.g.; needles) \\
Physiotherapy (Functional rehabilitation) & Mindfulness awareness & & Surgery/operations \\
The middle road (did not under/overdo things & Graded visual imagery & & \\
\hline
\end{tabular}

Consumers with low back pain were asked to indicate their use of self management strategies by choosing from the four categories listed above.

catastrophizing beliefs, as the subscale appears to demonstrate greater utility in terms of examining coping, appraisals, and pain adjustment compared to the composite scores [35]. This subscale lists 6 items which are scored using a 7-point Likert scale with responses 0 indicating 'never' to 6 indicating 'always'. Scores can range from 0-36 with higher scores indicating greater catastrophizing beliefs. The internal consistency of the subscale is reported to be $\alpha=0.85$ [36].

\section{Back pain beliefs}

Beliefs about the inevitable consequences of future life with low back problems was measured using the Back Beliefs Questionnaire (BBQ) $[37,38]$. The BBQ consists of 14 items, each of which is rated on a 5 point Likert scale, ranging from 1 (completely disagree) to 5 (completely agree), yielding a possible range of 9 to 45. A higher score indicates more positive beliefs, suggesting better ability to cope with LBP. The internal consistency $(\alpha=0.70)$ and test-retest reliability $(\mathrm{ICC}=0.87)$ of the BBQ have been established previously [38].

\section{Fear avoidance beliefs}

The Fear Avoidance Beliefs Questionnaire (FABQ) [39] was administered to assess fear avoidance beliefs around work and physical activity. Items are rated using a 7 point Likert scale, with 1 indicating 'completely agree' to 7 indicating 'completely disagree'. Two subscales are calculated with a total possible score of between 0-24 for the FABQ-physical and between 0-42 for FABQwork. For both subscales, a lower score is consistent with fewer fear-avoidance beliefs. Internal consistency for FABQ-physical and FABQ-work were reported as $\alpha=0.77$ and $\alpha=0.88$, respectively [39]. Thresholds of $>14$ (FABQ-P) and $>29$ (FABQ-W) suggest elevated fear avoidance beliefs [40].

\section{Emotional functioning}

A measure of negative emotional functioning was assessed using the Depression, Anxiety and Stress Scale (DASS21) [41]. The rating scale for DASS uses a 4 point Likert scale with 0 (indicating 'did not apply to me at all') to 3 (indicating 'applied to me very much, or most of the time'). As DASS is based on a quantitative dimensional measure of distress along the axes of depression, anxiety (symptoms of psychological arousal) and stress (the more cognitive, subjective symptoms of anxiety), we limited questions to the two top loading items for each subscale, determined through earlier factor analysis [42] and represented these within the rating categories outlined above (i.e.; indicating degree of difference). Questions and loading were as follows: depression: question 10 (.53) and question 21 (.42); for anxiety: question 7 (.46) and question 19 (.43); and for stress, question 1(.38) and question 14(.42) [42].

\section{Health literacy}

Information about the broader elements of health literacy [43] including the ability to seek, understand and utilize health information, was measured using the Health Literacy Measurement Scale (HeLMS) [44,45]. This tool consists of eight independent domains including patient attitudes towards health, understanding health information, social support, socio-economic considerations, accessing general practice healthcare services, communicating with health professionals, being proactive, and using health information. Each of the 29 items is rated on a 5 point Likert scale with the 1 indicating 'unable to do' to 5 indicating 'able to do without difficulty'. By summing and averaging the items for each domain, a score is calculated for each domain.

\section{Clinical usefulness of the mSTEPs intervention}

Consumers used a Global Perceived Impression of Usefulness (GPIU) scale to rate usefulness of the mSTEPs, 
scored with an 11-point NRS scale, 0 indicating 'not at all useful' to 10 indicating 'extremely useful' [46].

\section{Statistical analyses}

Demographic variables for participants were described using mean and standard deviation (SD) for continuous variables or frequencies and percentages for categorical variables. The within-subject changes in questionnaire scores from pre to post intervention were analyzed using dependent $\mathrm{t}$-tests. Responses for each HeLMS item were also dichotomized as 'no difficulty' (i.e.; a score of 5 on the Likert scale) or 'any difficulty' (i.e.; a score of 1-4 on the Likert scale) and the proportion of scores in each category was calculated, consistent with an earlier approach [47]. Statistical significance was set at $\alpha=0.05$.

\section{Results}

\section{Demographic and clinical data}

Demographic data are shown in Table 3 and health care utilization regarding LBP is shown in Table 4, while baseline clinical data are presented in Table 5 .

\section{Use of self-management strategies}

At baseline, a range of active and passive self-management approaches were reportedly used by consumers to help relieve their LBP (Table 5). On average, more active strategies were employed than passive strategies. The three most frequently nominated strategies within each of the four categories (data not shown) were: (i) active behavioural: did small bits often, modified activity, exercise and corrected posture/stretches (equal); (ii) active cognitive: relaxation, improved diet, ignored pain; (iii) passive: rest, hot bath/shower, massage; (iv) passive conventional: took medication, physiotherapy treatment and surgery/operation.

\section{Pain-related cognitive behavioural measures}

Baseline mean (SD) scores for each belief measure are shown in Table 5.

\section{Emotional functioning}

The majority of responses to the DASS fell into the 0 and 1 categories for all three dimensions (less negative emotional functioning) (Table 5). A small percentage of consumers endorsed either categories 2 and 3 for various items (suggesting more negative emotional functioning).

\section{Health literacy}

While the mean scores for each of the eight domains on the HeLMS ranged from 4.2 to 4.7, suggesting overall adequate health literacy, the range data highlight that some individuals experienced difficulty within some domains (Table 6). To indicate what proportion of consumers had any level of difficulty with an item, versus the proportion who reported no difficulty, a further

Table 3 Demographic characteristics of consumers with persistent low back pain

\begin{tabular}{|c|c|}
\hline Characteristic & \\
\hline \multicolumn{2}{|l|}{ Region in Western Australia } \\
\hline Kununurra & $6(11.8)$ \\
\hline Albany & $25(49.0)$ \\
\hline Kalgoorlie & $20(39.2)$ \\
\hline Age (years) $(N=50)$; mean $(S D)[$ min-max $]$ & $62.3(15.1)[27-86]$ \\
\hline Gender (Female) $(\mathrm{N}=48)$ & $33(68.8)$ \\
\hline English as a first language $(N=51)$ & $47(92.2)$ \\
\hline Born in Australia $(\mathrm{N}=50)$ & $31(62.0)$ \\
\hline \multicolumn{2}{|l|}{ Highest education level achieved $(\mathrm{N}=48)$} \\
\hline Completed up to 3 years secondary school & $10(20.8)$ \\
\hline Technical and Further Education / Vocational college & $8(16.8)$ \\
\hline Completed all 5 years of secondary school $\$$ & $12(25.0)$ \\
\hline University qualification & $18(37.5)$ \\
\hline Currently employed ( $\mathrm{N}=49)$ & $21(42.9)$ \\
\hline Medical benefits eligibility ${ }^{*}(N=51)$ & $27(52.9)$ \\
\hline Current insurance claim for injury $(\mathrm{N}=49)$ & $3(6.1)$ \\
\hline Seeing/planning to see a solicitor about their LBP $(N=50)$ & $1(2.0)$ \\
\hline
\end{tabular}

Consumers with persistent low back pain were recruited to the modified Self Training Educative Pain Sessions program which was conducted in three remote regions of Western Australia. Demographic data are presented as $n(\%)$ unless indicated otherwise

$\S$ In Western Australia, to complete High School requires 5 years of study; ${ }^{*}$ The Australian Federal Government funds a scheme which benefits recipients, including low income earners and selected other groups with access to subsidized prescription medicines and a lower Extended Medicare Safety Net threshold, both of which reduce out-of-pocket costs. 
Table 4 Health care utilisation for consumers with persistent low back pain

\begin{tabular}{ll}
\hline Previous treatment options accessed for LBP $(\mathbf{N}=\mathbf{4 9})$ & $\mathbf{N}(\%)$ \\
\hline General Practitioner (family physician) & $45(91.8)$ \\
Physiotherapist & $32(65.3)$ \\
Medical Specialist & $22(44.9)$ \\
Chiropractor & $21(42.9)$ \\
Clinical Psychologist & $6(12.2)$ \\
Psychiatrist & $5(10.2)$ \\
Acupuncturist & $14(28.6)$ \\
Naturopath & $3(6.1)$ \\
Osteopath & $4(8.2)$ \\
Rehabilitation specialist & $5(10.2)$ \\
Other ${ }^{\text {\& }}$ & $2(4.1)$
\end{tabular}

Consumers were asked to indicate what treatment options they had accessed in the past for the management of their persistent low back pain. The list included an option ('other' category) to indicate and specify health professionals additional to the below nominated categories

${ }^{\S}$ Two consumers nominated seeking treatment from a Bowen Therapist.

analysis was undertaken on each domain to examine the proportion of people who scored 1 to 4 on each item, versus those who scored 5.

\section{Same day immediately post-intervention evaluation}

There was a clinically-important increase in consumer BBQ scores $(\mathrm{N}=46)$ comparing baseline [mean $(\mathrm{SD})$ : 25.8 (7.6)] to same day post-intervention [28.8 (7.2)] [mean difference $(95 \% \mathrm{CI}):+3.0(0.9$ to 5.1$) ; \mathrm{P}=0.005$ ] indicating more positive consumer beliefs about back pain. The majority of consumers (86.4\%) rated mSTEPs as useful (NRS: 7 to 10), with a small proportion (9.1\%) indicating the intervention was moderately useful (NRS: 4 to 6$)$ and only $2(4.5 \%)$ consumers rating the intervention as not that useful (NRS: 0 to 3 ).

\section{Baseline to 3 month post-intervention evaluation}

Twenty five subjects (49\% response rate) responded to the three month postal questionnaire (Table 7). There were no baseline differences in demographic, clinical, health literacy or any belief measure between responders and non-responders.

Analysis of responders alone demonstrated for the same-day evaluation, a similar significant increase in BBQ scores as the whole group [mean difference (95\% $\mathrm{CI})$ : +2.8 (0.0 to 5.7$) ; \mathrm{P}=0.049$ ], but the improvement was not sustained at 3 months [mean decrease from same-day post $(95 \% \mathrm{CI})$ : $-2.0(-0.4$ to -3.6$) ; \mathrm{P}=0.018$ ]. The number of self-management strategies used by consumers did not change significantly and none of the pain-related cognitive-behavioural measures indicated any significant changes from baseline scores at 3 months post-intervention. Health care utilization and pain intensity measures did not change significantly (data not shown).

\section{Discussion}

This study evaluated the outcomes of delivering a consumer-oriented, evidence-based interdisciplinary pain education intervention, mSTEPS, to consumers with persistent LBP residing in three geographically-remote areas in WA. At baseline, consumers demonstrated scores suggesting positive back pain beliefs, adequate health literacy and positive health behaviours, the latter reflected by the use of more active than passive strategies in self-managing their persistent LBP. Immediately following mSTEPS, consumers' general beliefs about back pain were significantly more positive indicating a short term improvement in beliefs and the vast majority of consumers rated the program as useful. At 3 months post-mSTEPS intervention, there was no evidence for significant improvement in any baseline measure. This lack of longer term effect may reflect the already high baseline measures or could indicate that additional reinforcement strategies are required in order to sustain improvements in back pain beliefs. Whether a sustained improvement in back beliefs facilitates the adoption of more positive health behaviour is unclear, although it is likely that additional reinforcement strategies are required for this to occur.

In our study, general back pain-related attitudes and beliefs were similar to those reported in other Australian populations with and without LBP $[43,48,49]$ and to other international cohorts [50]. Immediately following mSTEPS, the clinically significant shift towards more positive beliefs about back pain and its consequences was an important outcome, given negative attitudes and beliefs in consumers with persistent LBP can significantly contribute to disability $[39,48,51,52]$. The magnitude of the positive shift was similar to that previously demonstrated following an Australian population-based intervention designed to improve beliefs about back pain $[51,53]$. However, the positive shift in the same-day beliefs in the present study was not sustained when examining differences in 3 month-responder scores at baseline (27.2 \pm 6.9$)$, same-day ( $30.3 \pm 7.0)$ and at 3 months post-intervention $(28.4 \pm 6.8)$. These consumers demonstrated a significant decrease in scores at 3 months from their significantly improved levels immediately post-course. The pattern of decrease in BBQ scores is unclear, as data were not collected between the sameday post and the 3 month test points. Therefore, we can safely surmise that a brief intervention such as mSTEPS, used as a stand-alone intervention, appears insufficient to generate a sustained improvement in back beliefs and it is likely that additional measures are 
Table 5 Baseline clinical characteristics for consumers with persistent low back pain

\begin{tabular}{|c|c|c|c|c|}
\hline \multicolumn{5}{|l|}{ Clinical characteristics } \\
\hline Current episode of LBP present more than 3 months $(N=50)$ & $46(92.0)$ & & & \\
\hline \multicolumn{5}{|l|}{ Current episode of LBP Intensity (NRS $\left.{ }^{\dagger} 0-10\right)$ (mean(sd)): } \\
\hline LBP now $(N=51)$ & $3.5(2.9)$ & & & \\
\hline LBP in last week $(N=51)$ & $5.0(2.8)$ & & & \\
\hline LBP in last 4 weeks $(N=51)$ & $4.8(2.4)$ & & & \\
\hline Functional limitations due to LBP & Activity $1(\mathrm{~N}=43)$ & \multicolumn{2}{|l|}{ Activity $2(\mathrm{~N}=38)$} & Activity $3(N=30)$ \\
\hline Exercise & $22(51.2)$ & \multicolumn{2}{|l|}{$13(34.2)$} & $8(26.7)$ \\
\hline Bending, lifting, carrying & $8(18.6)$ & \multicolumn{2}{|l|}{$8(21.1)$} & $8(26.7)$ \\
\hline Sustained postures & $7(16.3)$ & \multicolumn{2}{|l|}{$10(26.3)$} & $7(23.3)$ \\
\hline Housework or gardening & $4(9.3)$ & \multicolumn{2}{|l|}{$7(18.4)$} & $5(16.7)$ \\
\hline Hobbies & $2(4.7)$ & \multicolumn{2}{|l|}{0} & $2(6.7)$ \\
\hline \multicolumn{5}{|l|}{$\begin{array}{l}\text { Use of self management strategies } \\
\text { (count: mean (SD)) }(N=49)\end{array}$} \\
\hline Active Behavioural (total possible items $=9$ ) & \multicolumn{4}{|l|}{$3.6(2.2)$} \\
\hline Active Cognitive (total possible items $=9$ ) & \multicolumn{4}{|l|}{$2.6(2.1)$} \\
\hline Passive (total possible items $=7$ ) & \multicolumn{4}{|l|}{$2.4(1.6)$} \\
\hline $\begin{array}{l}\text { Passive Conventional Medical } \\
\text { (total possible items }=8 \text { ) }\end{array}$ & \multicolumn{4}{|l|}{$2.0(1.4)$} \\
\hline \multicolumn{5}{|l|}{$\begin{array}{l}\text { Pain-related cognitive-behavioural } \\
\text { scales (mean (SD)) }\end{array}$} \\
\hline$B B Q ;(N=49) ;$ possible score 9-45 & \multicolumn{4}{|l|}{$26.5(7.9)$} \\
\hline $\begin{array}{l}\text { CSQ:(Factor } 2 \text { subscale: } \\
\text { catastrophising)( } N=49) \text {; possible score } 0-36\end{array}$ & \multicolumn{4}{|l|}{$9.7(7.9)$} \\
\hline FABQ-Physical; $(N=50)$; possible score $0-24$ & \multicolumn{4}{|l|}{$14.3(6.4)$} \\
\hline FABQ-Work; $(N=43)$;possible score 0-42 & \multicolumn{4}{|l|}{$16.0(11.7)$} \\
\hline Emotional Functioning & 0 & 1 & 2 & 3 \\
\hline DASS $\S$ possible range 0-3 & $\begin{array}{l}\text { (did not apply } \\
\text { to me at all) }\end{array}$ & $\begin{array}{l}\text { (applied to me } \\
\text { some of the time) }\end{array}$ & $\begin{array}{l}\text { (applied to me a } \\
\text { good part of the time) }\end{array}$ & $\begin{array}{l}\text { (applied to me } \\
\text { most of the time) }\end{array}$ \\
\hline $10^{a}$ : Nothing to look forward to $(N=47)$ & $33(70.2)$ & $5(10.6)$ & $7(14.9)$ & $2(4.3)$ \\
\hline $22^{b}:$ Hard to wind down $(N=50)$ & $13(26.0)$ & $16(32.0)$ & $13(26.0)$ & $8(16.0)$ \\
\hline $\begin{array}{l}25^{c} \text { : Aware of the action of my heart in the } \\
\text { absence of physical exertion }(N=45)\end{array}$ & $25(55.5)$ & $9(20.0)$ & $8(17.8)$ & $3(6.7)$ \\
\hline $\begin{array}{l}35^{b} \text { : Intolerant of anything that kept me from } \\
\text { getting on with what I was doing }(N=48)\end{array}$ & $18(37.5)$ & $16(33.3)$ & $8(16.7)$ & $6(12.5)$ \\
\hline $38^{a}$ Felt that life was meaningless $(N=48)$ & $35(72.9)$ & $7(14.6)$ & $4(8.3)$ & $2(4.2)$ \\
\hline $41^{c}$ : Experienced trembling $(N=48)$ & $29(60.4)$ & $9(18.7)$ & $8(16.7)$ & $2(4.2)$ \\
\hline
\end{tabular}

Measures included pain intensity, pain duration, functional limitations, use of active and passive self management strategies, back pain beliefs (BBQ), catastrophizing beliefs (CSQ), fear avoidance beliefs regarding work (FABQ-W) and physical activity (FABQ-P), and factors which load to depression, anxiety and stress (DASS). Data are presented as $n(\%)$ unless indicated otherwise

LBP: low back pain; +VAS: Visual Analogue Scale; ${ }^{\S}$ The two top loading items from each of the three self-report scales of the Depression, Anxiety, Stress Scale (DASS) were used and the scales for each questions are identified as follows: ${ }^{a}$ Depression scale; ${ }^{b}$ Stress scale; ${ }^{c}$ Anxiety scale.

required to achieve a sustained positive shift in consumer back pain beliefs. Support measures may involve the repetition of simple evidence-based messages using multimedia [53,54]; supplemental educational written materials [50]; reinforcing strategies delivered via internet-based educational approaches [55]; or active management and group-based cognitive-behavioural approaches [56,57]. The use of internet approaches may be particularly well-suited to geographically-isolated consumers with LBP. Furthermore, we suggest that regular community-based group sessions for consumers with LBP with limited access to pain services and community 
Table 6 The Health Literacy Measurement Scale (HeLMS) was used to measure consumers' health literacy

\begin{tabular}{|c|c|c|c|c|}
\hline Domain (number/title) & Mean (SD) & Min-max & Range (\%) $1-4^{*}$ & Range (\%) $5^{\S}$ \\
\hline 1. Patient attitudes towards their health & $4.5(0.6)$ & $3.0-5.0$ & $6.0-49.0$ & $51.0-94.0$ \\
\hline 2. Understanding health information & $4.4(0.6)$ & $2.3-5.0$ & $22.0-61.0$ & $39.0-78.0$ \\
\hline 3. Social support & $4.5(0.6)$ & $2.8-5.0$ & $22.0-51.0$ & $49.0-78.0$ \\
\hline 4. Socioeconomic factors: accessing healthcare services & $4.7(0.5)$ & $2.7-5.0$ & $7.8-19.6$ & $80.4-92.2$ \\
\hline 5. Accessing general practitioner (GP) healthcare services & $4.5(0.5)$ & $2.7-5.0$ & $15.7-34.0$ & $66.0-84.3$ \\
\hline 6. Communicating with health professionals & $4.2(0.8)$ & $1.3-5.0$ & $24.0-70.6$ & $29.4-76.0$ \\
\hline 7. Being proactive & $4.4(0.6)$ & $3.0-5.0$ & $24.0-58.8$ & $41.2-76.0$ \\
\hline 8. Using health information & $4.5(0.7)$ & $1.75-5.0$ & $8.2-44.0$ & $56.0-91.8$ \\
\hline
\end{tabular}

Consumers' ( $\mathrm{N}=50)$ ability to seek, understand and use health information is shown. Mean score (SD) and range data for each of the eight domains are presented. The possible score for each item within a domain ranged from 1: unable to do to 5: able to do without any difficulty

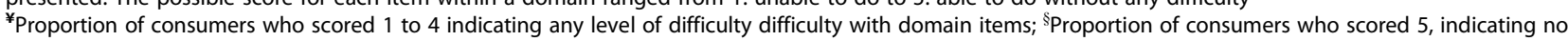
difficulty with domain items.

support $[12,20]$, should be considered by health funding bodies, given the available data demonstrating their cost effectiveness and positive health outcomes [57]. Collectively, our findings suggest that it is important to use any transient change in beliefs as a potential 'therapeutic window' to encourage the adoption of positive behavioural change, as beliefs and behaviour for consumers with persistent LBP do not necessarily match [43].

In our study cohort, pain catastrophizing scores were lower compared with those previously reported for people with persistent LBP [58], but higher than those reported for a younger WA urban population with persistent LBP and high disability [43]. Half of the consumers in the present study had elevated fear avoidance beliefs scores, similar to those reported in other LBP populations $[59,60]$. The need for these cognitive and emotional factors to be addressed is highlighted given that catastrophizing and elevated fear avoidance beliefs can interfere with the adoption of beneficial health behaviours [61]. In this context, the use of timely cognitive-behavioural group sessions, which appear to provide reassurance, lessen isolation and enable participants to learn strategies from each other and re-engage earlier into the workforce [57], could align well with the delivery of a community-based LBP management program. The manner in which messages are conveyed to consumers by health professionals should also be considered as our data highlight a proportion of consumers have some level of difficulty understanding health information and communicating with health professionals, while other evidence points to poor quality communication strategies adopted by health professionals in the context of LBP, particularly with consumers who experience persistent LBP [62].

For treatment of their LBP, consumers accessed primarily general practitioners and physiotherapists or chiropractors, possibly reflecting the available services and accessibility. Notably, almost half of the cohort had also

Table 7 Comparison data (mean(SD); baseline and 3 months post-intervention) for responders with persistent low back pain

\begin{tabular}{|c|c|c|c|}
\hline Self report measures & $\begin{array}{l}\text { Baseline } \\
\text { Mean(SD) }\end{array}$ & $\begin{array}{l}3 \text { months post } \\
\text { Mean(SD) }\end{array}$ & $\begin{array}{l}\text { Difference } \\
\text { (Mean; 95\% Cl) }\end{array}$ \\
\hline \multicolumn{4}{|l|}{ Self management strategies } \\
\hline Active Behavioural (total possible items $=9$ ) & $4.3(2.4)$ & $4.5(2.4)$ & $+0.1(-0.9,+1.1)$ \\
\hline Active Cognitive (total possible items $=9$ ) & $3.0(2.5)$ & $2.3(1.9)$ & $-0.7(-1.5,+0.0)$ \\
\hline Passive (total possible items $=7$ ) & $3.0(1.7)$ & $2.8(1.3)$ & $-0.2(-0.8,+0.4)$ \\
\hline Passive Conventional Medical (total possible items $=8$ ) & $2.3(1.7)$ & $1.9(1.7)$ & $-0.4(-1.4,+0.6)$ \\
\hline \multicolumn{4}{|l|}{ Pain-related cognitive-behavioural scales } \\
\hline BBQ score; $(N=23)$ & $27.2(6.9)$ & $28.4(6.8)$ & $+1.2(-1.4,3.8)$, \\
\hline CSQ score:(Factor 2 subscale: catastrophising) $(N=20)$ & $9.7(7.9)$ & $8.6(8.1)$ & $-1.2(-5.0,2.6)$ \\
\hline FABQ-Physical score; $(N=24)$ & $14.0(6.0)$ & $12.3(6.2)$ & $-1.7(-3.9,0.5)$, \\
\hline FABQ-Work score; $(N=23)$ & $16.7(9.7)$ & $17.9(10.9)$ & $+1.3(-3.2,5.7)$, \\
\hline
\end{tabular}

Post mSTEPS, no significant differences were demonstrated in responders' $(\mathrm{N}=23)$ use of active or passive self management strategies or their pain-related cognitive-behavioural measures

BBQ: Back Beliefs Questionnaire; CSQ: Coping Skills Questionnaire: subscale 2: catastrophizing; FABQ: Fear Avoidance Beliefs Questionnaire. 
consulted a specialist regarding their persistent LBP, and on most occasions, this would have required them to visit a tertiary facility in Perth. The provision of additional services to assist in reinforcing key health messages and to encourage positive health behaviour could be achieved, in part through community-based educational programs combined delivered by 'virtual' interdisciplinary teams using novel information technologies, or by the provision of reliable, accessible and evidencebased information resources at the community level, a need previously highlighted by consumers [27]. Such innovative solutions could potentially improve health system efficiencies by providing opportunities to simultaneously upskill both health care professionals and consumers and reduce the need for these consumers to travel to tertiary centres, thereby supporting contemporary health policy directions.

An additional and important component of any optimal model of care for the management of persistent LBP is the facilitation of consumer use of active cognitive and behavioural self-management strategies [23-25]. At baseline, consumers used more active cognitive-behavioural self management strategies than an urban WA population of consumers with persistent spinal pain [25] and more active than passive strategies. Using active strategies to assist in self-managing persistent LBP is important as such approaches substantially reduce the likelihood of consumers having high levels of painrelated disability [23]. Furthermore, adherence to specific self-management strategies can predict reductions in pain, disability and depressive symptoms even after controlling for the moderating effects of catastrophizing, fear-avoidance and pain self-efficacy beliefs [63]. In our study, consumers most frequently employed simple active behavioural approaches that aligned well with their functional limitations, however associated qualitative data from a subset of these consumers suggests that assistance may be required with the adoption and maintenance of long term self management strategies [27]. This may be particularly true for those consumers (up to $71 \%$ ) reporting difficulty with the broader elements of health literacy, potentially reducing their capacity to engage in positive lifestyle behaviours [27].

Active self management behaviours did not increase significantly at 3 months, although at baseline use of these strategies was already quite high. Several factors which impinge and encourage uptake of self-management strategies have been identified $[23,64]$, and require consideration in the context of our cohort. These can be summarized as follows: 1) limited resources and access to resources; 2 ) ineffectiveness of pain-relief strategies (evident by those passive conventional strategies chosen by consumers as not helping to relieve their LBP and which included surgery, operations, physiotherapy, chiropractic, acupuncture and medication); 3) time constraints and other life priorities ([27,43]; 4) avoiding activity because of fear of pain exacerbation; 5) a lack of tailoring strategies to meet personal needs (possibly incorporating the lack of coordinated interdisciplinary care or limited access to such services); 6) not being able to maintain the use of strategies after the mSTEPS intervention; 7) physical limitations (reflected in consumers' functional limitations); 8) sub-optimal patientphysician interactions; 9) difficulty in the broader aspects of health literacy.

Standardized evidence-based approaches to chronic health conditions with flexible and tailored self-management and personalized co-care plans could better match consumer needs to resources $[65,66]$, although readiness for change [67] and adherence to these evidence-based approaches is important in optimizing patient outcomes $[68,69]$. To encourage appropriate service delivery and facilitate the uptake of active self-management and co-care for consumers with persistent spinal pain, we recommend that policy makers and health professionals address the following key considerations: 1) timely provision of integrated evidence-based interdisciplinary co-care $[70,71]$; 2) ensuring the availability of supportive health professionals [72] and carers; 3) providing a menu of different self-management strategies allowing better matching of consumer profiles with appropriate resources to optimize health outcomes [66,73]; 4) facilitating adherence to self management [63] and providing reinforcement to help encourage the adoption of positive behavioural change $[64,74]$ with reference to an operationalized stages of change framework [75] and readiness to adopt self management [67]. To address these changes requires system plasticity at the individual level (preferably using a whole person engagement model, which we term the HOPE model), in primary care (appropriately skilled interdisciplinary workforce), at a community level (community-based training programs), and at a tertiary level (integrated interdisciplinary co-care). The novel use of information technologies may facilitate such system plasticity for the benefit of health consumers living in geographically-isolated areas.

Our study has several limitations and the applicability of these findings to other populations of consumers with persistent LBP may be limited because of the following factors: a randomized controlled trial would strengthen the study design, as currently the lack of a control group precludes a comparison of the natural time course of outcome measures with change specifically attributed to mSTEPS; data were based on self-report measures; a modest sample size (therefore we cannot control reliably for potential confounding factors like socio-economic status, high and low disability); responder bias (response rate of 49\%); and selection bias (consumers in this study were predominantly female $(68.8 \%)$ and educated 
(62\% had completed high school)). Additionally, consumers were self-referred to mSTEPS and their motivations for attending this educational intervention may differentiate them from consumers not seeking care for persistent LBP.

\section{Conclusions}

The implementation of health policy through a consumeroriented intervention, set within a contemporary pain management evidence-based framework, can be successfully delivered within primary care. In order to focus management on the whole person and to encourage positive consumer health behaviour, appropriate post-intervention support systems, including access to health services and to appropriately skilled workforce, are recommended. Our findings highlight the need for health delivery change if the current best research in spinal pain is to be effectively and sustainability translated from policy into practice for consumers with persistent LBP living in remote areas.

\section{Additional file}

\section{Additional file 1: Components of the modified Self Training} Educative Pain Sessions.

\section{Abbreviations}

LBP: Low back pain; mSTEPS: Modified Self Training Educative Pain Sessions (STEPS) program; CSQ: Coping Skills Questionnaire; BBQ: Back pain beliefs questionnaire; FABQ: Fear avoidance beliefs questionnaire; DASS: Depression, Anxiety and Stress Scale; HeLMS: Health Literacy Measurement Scale.

\section{Competing interests}

The authors declare they have no competing interests.

\section{Authors' contributions}

$H S, A B, S D, A S$, and JQ contributed to the study design and coordination. SB managed the data collection and entry. AS completed the statistical analyses. $H S, A B$ and $A S$ interpreted and reported on the data. All authors contributed to the intellectual content of the manuscript and the manuscript preparation. HS drafted the first and final manuscript versions and acts as guarantor of the paper. All authors contributed to editing the manuscript, contributed to revisions and approved the final manuscript.

\section{Authors' information}

HS is a clinical researcher and a Specialist Musculoskeletal Physiotherapist with Honorary position at Fremantle Hospital, Pain Medicine Unit. AB is a senior researcher supported by a Fellowship from the Australian National Health and Medical Research Council (NHMRC). SD is a Pain a Medicine Specialist and Head of the Fremantle Hospital, Pain Medicine Unit and Director is Statewide (WA) Pain Medicine Services. AS is a senior researcher and biostatistician who is supported by a Fellowship from Curtin University. JQ is a Rheumatologist and Pain Medicine Specialist. SB is a doctoral student and research assistant.

\section{Disclosures}

The following authors received honoraria for delivering the mSTEPS programs: SD and JQ.

\section{Acknowledgements}

The authors acknowledge financial and in kind support from the Department of Health (Government of Western Australia), Arthritis and Osteoporosis WA, Rural Health West, School of Physiotherapy, Curtin University, the Pain Medicine Unit at Fremantle Hospital Health Service, and the WA Musculoskeletal Health Network. Elizabeth Forrester, Melanie Galbraith, Eric Visser, Carl Graham, Jennifer Roe, Sue Wilkinson and Diana Barron are acknowledged for their contribution to the regional education forums. The WA State Health Research Advisory Council (SHRAC) translational research scheme is acknowledged for providing competitive grant funding to develop the original STEPS project in 2007-2008.

\section{Author details}

${ }^{1}$ School of Physiotherapy, Curtin University, Perth, Australia. ${ }^{2}$ Curtin Health Innovation Research Institute, Curtin University, Perth, Australia. ${ }^{3}$ Department of Health, Government of Western Australia, Perth, Australia. ${ }^{4}$ Pain Medicine

Unit, Fremantle Hospital and Health Service, Perth, Australia.

Received: 21 November 2011 Accepted: 20 April 2012

Published: 11 May 2012

\section{References}

1. MBF Foundation: The high price of pain: the economic impact of persistent pain in Australia. In Edited by. : Report conducted by Access Economics in collaboration with the University of Sydney University of Sydney Pain Management Research Institute; 2007.

2. Henry JL: The need for knowledge translation in chronic pain. Pain Res Manag 2008, 13(6):465-476.

3. Walsh NE, Brooks P, Hazes JM, Walsh RM, Dreinhofer K, Woolf AD, Akesson K, Lidgren L: Standards of care for acute and chronic musculoskeletal pain: the Bone and Joint Decade (2000-2010). Arch Phys Med Rehabil 2008, 89(9):1830-1845.

4. McGuirk B, Bogduk N: Evidence-based care for low back pain in workers eligible for compensation. Occup Med (Lond) 2007, 57(1):36-42.

5. Overmeer T, Linton SJ, Holmquist L, Eriksson M, Engfeldt P: Do evidencebased guidelines have an impact in primary care? A cross-sectional study of Swedish physicians and physiotherapists. Spine 2005, 30(1): 146-151.

6. Buchbinder R, Staples M, Jolley D: Doctors with a special interest in back pain have poorer knowledge about how to treat back pain. Spine 2009, 34(11):1218-1226. discussion 1227.

7. Fullen BM, Baxter GD, O'Donovan BGG, Doody C, Daly LE, Hurley DA Factors impacting on doctors' management of acute low back pain: a systematic review. Eur J Pain 2009, 13(9):908-914.

8. Breen A, Austin H, Campion-Smith C, Carr E, Mann E: "You feel so hopeless": a qualitative study of GP management of acute back pain. Eur J Pain 2007, 11(1):21-29.

9. Breen AC, Carr E, Langworthy JE, Osmond C, Worswick L: Back pain outcomes in primary care following a practice improvement intervention:- a prospective cohort study. BMC Musculoskelet Disord 2011 $12: 28$.

10. Krismer M, van Tulder M: Strategies for prevention and management of musculoskeletal conditions. Low back pain (non-specific). Best Pract Res Clin Rheumatol 2007, 21(1):77-91.

11. Department of Health Western Australia: Spinal pain model of care. In Spinal pain model of care. Edited by Department of Health, Health Networks Branch, Western Australia. Perth: Department of Health WA; 2009.

12. Deyo RA, Mirza SK, Turner JA, Martin Bl: Overtreating chronic back pain: time to back off? J Am Board Fam Med 2009, 22(1):62-68.

13. Slade SC, Molloy E, Keating JL: Stigma experienced by people with nonspecific chronic low back pain: a qualitative study. Pain Med 2009, 10 (1):143-154.

14. Cohen M, Quintner J, Buchanan D, Nielsen M, Guy L: Stigmatization of patients with chronic pain: the extinction of empathy. Pain Med 2011, early online.

15. Apkarian AV, Hashmi JA, Baliki MN: Pain and the brain: specificity and plasticity of the brain in clinical chronic pain. Pain 2011, 152(3 Suppl): S49-64

16. Borsook D, Moulton EA, Schmidt KF, Becerra LR: Neuroimaging revolutionizes therapeutic approaches to chronic pain. Mol Pain 2007, 3:25.

17. Baliki MN, Geha PY, Apkarian AV: Parsing pain perception between nociceptive representation and magnitude estimation. J Neurophysiol 2009, 101(2):875-887

18. Tracey I, Bushnell MC: How neuroimaging studies have challenged us to rethink: is chronic pain a disease? J Pain 2009, 10(11):1113-1120. 
19. Domenech J, Sanchez-Zuriaga D, Segura-Orti E, Espejo-Tort B, Lison JF: Impact of biomedical and biopsychosocial training sessions on the attitudes, beliefs, and recommendations of health care providers about low back pain: a randomised clinical trial. Pain 2011, 152(11):2557-2563.

20. McGrath P: 'The biggest worry': research findings on pain management for Aboriginal peoples in Northern Territory, Australia. Rural Remote Heal 2006, 6(3):549.

21. Australian Bureau of Statistics: Regional Population Growth, 2009-2010. Book Regional Population Growth, 2009-2010. Canberra: Australian Bureau of Statistics; 2010 [http://www.abs.gov.au/ausstats/abs@.nsf/mf/3218.0]

22. Australian and New Zealand College of Anaesthetists, Faculty of Pain Medicine: National Pain Strategy. Melbourne: 2010.

23. Blyth FM, March LM, Nicholas MK, Cousins MJ: Self-management of chronic pain: a population-based study. Pain 2005, 113(3):285-292

24. Tveito TH, Shaw WS, Huang YH, Nicholas M, Wagner G: Managing pain in the workplace: a focus group study of challenges, strategies and what matters most to workers with low back pain. Disabil Rehabil 2010, 32 (24):2035-2045.

25. Davies S, Quintner J, Parsons R, Parkitny L, Knight P, Forrester E, Roberts M, Graham C, Visser E, Antill T, et al: Preclinic group education sessions reduce waiting times and costs at public pain medicine units. Pain Med 2011, 12(1):59-71.

26. Blyth FM, March LM, Cousins MJ: Chronic pain-related disability and use of analgesia and health services in a Sydney community. Med J Aust 2003, 179(2):84-87.

27. Briggs A, Slater H, Davies S, Quintner J: The Western Australian Spinal Pain Model of Care: Translating evidence into public health policy and practice using Health Networks [abstract]. In Proceedings of the Australian Physiotherapy Association, Physiotherapy Conference 2011: 27-30th October, 2011. Edited by Australian Physiotherapy Association. Brisbane: 2011.

28. Turk DC, Dworkin RH, Burke LB, Gershon R, Rothman M, Scott J, Allen RR, Atkinson JH, Chandler J, Cleeland C, et al: Developing patient-reported outcome measures for pain clinical trials: IMMPACT recommendations. Pain 2006, 125(3):208-215.

29. Turk DC, Dworkin RH, Revicki D, Harding G, Burke LB, Cella D, Cleeland CS, Cowan P, Farrar JT, Hertz S, et al: Identifying important outcome domains for chronic pain clinical trials: an IMMPACT survey of people with pain. Pain 2008, 137(2):276-285.

30. Haythornthwaite JA: IMMPACT recommendations for clinical trials: opportunities for the RDC/TMD. J Oral Rehabil 2010, 37(10):799-806.

31. Kuorinka I, Jonsson B, Kilbom A, Vinterberg H, Biering-Sorensen F, Andersson G, Jorgensen K: Standardised Nordic questionnaires for the analysis of musculoskeletal symptoms. Appl Ergon 1987, 18(3):233-237.

32. Jensen MP, Turner JA, Romano JM, Fisher LD: Comparative reliability and validity of chronic pain intensity measures. Pain 1999, 83(2):157-162

33. Brown GK, Nicassio PM: Development of a questionnaire for the assessment of active and passive coping strategies in chronic pain patients. Pain 1987, 31(1):53-64.

34. Rosenstiel AK, Keefe FJ: The use of coping strategies in chronic low back pain patients: relationship to patient characteristics and current adjustment. Pain 1983, 17(1):33-44.

35. Geisser ME, Robinson ME, Henson CD: The coping strategies questionnaire and chronic pain adjustment: a conceptual and empirical reanalysis. Clin J Pain 1994, 10(2):98-106

36. Harland NJ, Georgieff K: Development of the coping strategies questionnaire 24 , a clinically utilitarian version of the coping strategies questionnaire. Rehabil Psychol 2003, 48(4):296-300.

37. Symonds $T L$, Burton AK, Tillotson KM, Main CJ: Absence resulting from low back trouble can be reduced by psychosocial intervention at the work place. Spine 1995, 20(24):2738-2745

38. Symonds TL, Burton AK, Tillotson KM, Main CJ: Do attitudes and beliefs influence work loss due to low back trouble? Occup Med (Lond) 1996, 46 (1):25-32.

39. Waddell G, Newton M, Henderson I, Somerville D, Main CJ: A FearAvoidance Beliefs Questionnaire (FABQ) and the role of fear-avoidance beliefs in chronic low back pain and disability. Pain 1993, 52(2):157-168.

40. George SZ, Fritz JM, Childs JD: Investigation of elevated fear-avoidance beliefs for patients with low back pain: a secondary analysis involving patients enrolled in physical therapy clinical trials. J Orthop Sports Phys Ther 2008, 38(2):50-58.
41. Lovibond PF, Lovibond SH: The structure of negative emotional states: comparison of the Depression Anxiety Stress Scales (DASS) with the beck depression and anxiety inventories. Behav Res Ther 1995, 33(3): 335-343.

42. Henry JD, Crawford JR: The short-form version of the Depression Anxiety Stress Scales (DASS-21): construct validity and normative data in a large non-clinical sample. Br J Clin Psychol 2005, 44(Pt 2):227-239.

43. Briggs AM, Jordan JE, Buchbinder R, Burnett AF, O'Sullivan PB, Chua JY, Osborne RH, Straker LM: Health literacy and beliefs among a community cohort with and without chronic low back pain. Pain 2010, 150(2): 275-283.

44. Jordan JE: Conceptualising and measuring health literacy from the patient perspective. In PhD thesis. Edited by. : University of Melbourne; 2009.

45. Jordan JE, Osborne RH, Buchbinder R: Critical appraisal of health literacy indices revealed variable underlying constructs, narrow content and psychometric weaknesses. J Clin Epidemiol 2011, 64(4):366-379.

46. Kamper SJ, Ostelo RW, Knol DL, Maher CG, de Vet HC, Hancock MJ: Global Perceived Effect scales provided reliable assessments of health transition in people with musculoskeletal disorders, but ratings are strongly influenced by current status. J Clin Epidemiol 2010, 63(7):760-766. e761.

47. Briggs AM, Jordan JE, O'Sullivan PB, Buchbinder R, Burnett AF, Osborne RH, Straker LM: Individuals with chronic low back pain have greater difficulty in engaging in positive lifestyle behaviours than those without back pain: An assessment of health literacy. BMC Musculoskelet Disord 2011, $12: 161$

48. Urquhart DM, Bell RJ, Cicuttini FM, Cui J, Forbes A, Davis SR: Negative beliefs about low back pain are associated with high pain intensity and high level disability in community-based women. BMC Musculoskelet Disord 2008, 9:148.

49. Buchbinder R, Jolley D, Wyatt M: Population based intervention to change back pain beliefs and disability: three part evaluation. BMJ 2001, 322 (7301):1516-1520.

50. George SZ, Teyhen DS, Wu SS, Wright AC, Dugan JL, Yang G, Robinson ME, Childs JD: Psychosocial education improves low back pain beliefs: results from a cluster randomized clinical trial (NCT00373009) in a primary prevention setting. Eur Spine J 2009, 18(7):1050-1058.

51. Buchbinder $R$, Jolley $D$ : Effects of a media campaign on back beliefs is sustained 3 years after its cessation. Spine (Phila Pa 1976) 2005, 30 (11):1323-1330

52. Linton SJ: A review of psychological risk factors in back and neck pain. Spine 2000, 25(9):1148-1156.

53. Buchbinder R, Jolley D: Effects of a media campaign on back beliefs is sustained 3 years after its cessation. Spine 2005, 30(11):1323-1330.

54. Waddell G, O'Connor M, Boorman S, Torsney B: Working Backs Scotland: a public and professional health education campaign for back pain. Spine 2007, 32(19):2139-2143.

55. Schulz PJ, Rubinell S, Hartung U: An internet-based approach to enhance self-managementof chronic low back pain in the italian-speaking population of Switzerland: results from a pilot study. Int J Public Health 2007, 52(5):286-294.

56. Johnson RE, Jones GT, Wiles NJ, Chaddock C, Potter RG, Roberts C, Symmons DP, Watson PJ, Torgerson DJ, Macfarlane GJ: Active exercise, education, and cognitive behavioral therapy for persistent disabling low back pain: a randomized controlled trial. Spine 2007, 32(15):1578-1585.

57. Lamb SE, Lall R, Hansen Z, Castelnuovo E, Withers EJ, Nichols V, Griffiths F, Potter R, Szczepura A, Underwood M: A multicentred randomised controlled trial of a primary care-based cognitive behavioural programme for low back pain. The Back Skills Training (BeST) trial. Health Technol Assess 2010, 14(41):1-253. iii-iv.

58. Boersma K, Linton SJ: How does persistent pain develop? An analysis of the relationship between psychological variables, pain and function across stages of chronicity. Behav Res Ther 2005, 43 (11):1495-1507

59. Crombez G, Vlaeyen JW, Heuts PH, Lysens R: Pain-related fear is more disabling than pain itself: evidence on the role of pain-related fear in chronic back pain disability. Pain 1999, 80(1-2):329-339.

60. George SZ, Fritz JM, Bialosky JE, Donald DA: The effect of a fear-avoidancebased physical therapy intervention for patients with acute low back pain: results of a randomized clinical trial. Spine 2003, 28(23):2551-2560. 
61. Picavet HS, Vlaeyen JW, Schouten JS: Pain catastrophizing and kinesiophobia: predictors of chronic low back pain. Am J Epidemiol 2002 156(11):1028-1034.

62. Gulbrandsen P, Madsen HB, Benth JS, Laerum E: Health care providers communicate less well with patients with chronic low back pain-a study of encounters at a back pain clinic in Denmark. Pain 2010, 150(3): 458-461.

63. Nicholas MK, Asghari A, Corbett M, Smeets RJ, Wood BM, Overton S, Perry C, Tonkin $L E$, Beeston $L$ : Is adherence to pain self-management strategies associated with improved pain, depression and disability in those with disabling chronic pain? Eur J Pain 2012, 16:93-104.

64. Bair MJ, Matthias MS, Nyland KA, Huffman MA, Stubbs DL, Kroenke K, Damush TM: Barriers and facilitators to chronic pain self-management: a qualitative study of primary care patients with comorbid musculoskeletal pain and depression. Pain Med 2009, 10(7):1280-1290.

65. Benjaminsson O, Biguet G, Arvidsson I, Nilsson-Wikmar L: Recurrent low back pain: relapse from a patients perspective. J Rehabil Med 2007, 39 (8):640-645.

66. Damush TM, Wu J, Bair MJ, Sutherland JM, Kroenke K: Self-management practices among primary care patients with musculoskeletal pain and depression. J Behav Med 2008, 31(4):301-307.

67. McCracken LM, Turk DC: Behavioral and cognitive-behavioral treatment for chronic pain: outcome, predictors of outcome, and treatment process. Spine 2002, 27(22):2564-2573.

68. Nicholas MK: On adherence to self-management strategies. Eur $J$ Pain 2009, 13(2):113-114

69. Wilk V, Palmer HD, Stosic RG, McLachlan AJ: Evidence and practice in the self-management of low back pain: findings from an Australian internetbased survey. Clin J Pain 2010, 26(6):533-540.

70. Staiger PK, Serlachius A, Macfarlane S, Anderson S, Chan T, Young G: Improving the coordination of care for low back pain patients by creating better links between acute and community services. Aust Health Rev 2010, 34(2):139-143.

71. Davies SJ, Hayes C, Quintner JL: System plasticity and integrated care: informed consumers guide clinical reorientation and system reorganization. Pain Med 2011, 12(1):4-8.

72. Matthias MS, Bair MJ, Nyland KA, Huffman MA, Stubbs DL, Damush TM, Kroenke K: Self-management support and communication from nurse care managers compared with primary care physicians: a focus group study of patients with chronic musculoskeletal pain. Pain Manag Nurs 2010, 11(1):26-34.

73. Kroenke K, Bair MJ, Damush TM, Wu J, Hoke S, Sutherland J, Tu W: Optimized antidepressant therapy and pain self-management in primary care patients with depression and musculoskeletal pain: a randomized controlled trial. JAMA 2009, 301(20):2099-2110.

74. Cooper K, Smith BH, Hancock E: Patients' perceptions of self-management of chronic low back pain: evidence for enhancing patient education and support. Physiotherapy 2009, 95(1):43-50.

75. Dijkstra A: The validity of the stages of change model in the adoption of the self-management approach in chronic pain. Clin J Pain 2005, 21(1): 27-37. discussion 69-72.

\section{Submit your next manuscript to BioMed Central and take full advantage of:}

- Convenient online submission

- Thorough peer review

- No space constraints or color figure charges

- Immediate publication on acceptance

- Inclusion in PubMed, CAS, Scopus and Google Scholar

- Research which is freely available for redistribution 